\title{
Efficacy of pneumatic displacement with 40 - degree downward gaze positioning for treatment of submacular hemorrhage: report of two cases
}

This article was published in the following Dove Press journal:

Clinical Ophthalmology

7 November 2012

Number of times this article has been viewed

\section{Masami Nakajima \\ Hiroshi Aso \\ Kohki Nakayasu}

Department of Ophthalmology, Division of Visual Science, Nihon University School of Medicine, Tokyo, Japan
Correspondence: Masami Nakajima Department of Ophthalmology, Division of Visual Science, Nihon University School of Medicine, 30-I

Oyaguchi-kamimachi, Itabashi, Tokyo

|73-8610, Japan

$\mathrm{Tel}+81339728 \mathrm{II}$ I

Fax +8135995 3495

Email nakajima.masami@nihon-u.ac.jp
Background: Two retrospective case reports are described showing the efficacy of pneumatic displacement with 40-degree downward gaze positioning for treatment of submacular hemorrhage. Case 1 involved an 85-year-old woman who visited our clinic with a complaint of blurred vision in her right eye. Best corrected visual acuity (BCVA) of the right eye was hand motion. Her right eye showed a submacular hemorrhage with retinal macroaneurysm. Prone positioning was difficult because of the patient's age and obesity. The treatment method was pneumatic displacement with 40-degree downward gaze positioning after intravitreal injection of $100 \%$ sulfur hexafluoride gas. After the treatment, the hemorrhage moved downward and BCVA of her right eye was 0.1 . Case 2 involved a 58-year-old man with a complaint of blurred vision in his left eye. BCVA of his left eye was 0.3 and submacular hemorrhage was observed. He underwent displacement of the hemorrhage as previously described. After treatment, the submacular hemorrhage moved downward. Angiography detected a polypoidal lesion with a vascular network. upon diagnosis of polypoidal choroidal vasculopathy, bevacizumab was injected intravitreally. Two months after gas injection, the submacular hemorrhage disappeared. Optical coherence tomography showed flattening of the submacular retinal pigment epithelium, which was not observed prior to bevacizumab therapy. BCVA of the patient's left eye was 0.9 . Pneumatic displacement with 40-degree downward gaze positioning after intravitreal sulfur hexafluoride injection is useful to displace a submacular hemorrhage. Early application of this treatment provides improvement of vision and facilitates fundus examination, which could reveal the cause of the submacular hemorrhage.

Keywords: 40-degree downward gaze position, submacular hemorrhage, intravitreal gas injection, sulfur hexafluoride, perfluoropropane

\section{Introduction}

Subretinal hemorrhages involving the macular area can cause severe deterioration of visual acuity. They are linked to age-related macular degeneration and retinal macroaneurysm. Displacement of the submacular hemorrhage before irreversible change of photoreceptor cells is preferred to improve vision and facilitate fundus examination to find the underlying cause of the hemorrhage. In animal studies, subretinal hemorrhage causes retinal damage in early phases, due to iron toxicity, barrier effects of a blood clot, and/or tractional forces to the photoreceptor cells. ${ }^{1,2}$ Prone positioning after intravitreal gas injection is a useful method to displace the submacular hemorrhage. ${ }^{3,4}$ However, prolonged prone positioning may cause physical and psychological suffering, such as low back pain, stiff neck, and insomnia. Because of these side effects, some of the patients could not continue to maintain the prone position. Pneumatic treatment with 40-degree downward gaze positioning after 
intravitreal perfluoropropane or perfluoroethane injection was reported to be useful to displace the submacular hemorrhage. ${ }^{5}$ We applied the 40-degree downward gaze positioning method using sulfur hexafluoride to replace perfluoropropane or perfluoroethane, with good results.

\section{Case report I}

An 85-year-old woman visited the clinic on September 30, 2010 with a complaint of sudden onset of blurred vision in her right eye 5 days prior. She had a history of systemic hypertension and Hashimoto's disease. She had presented with a subarachnoid hemorrhage at the age of 70 years, and underwent cataract surgery on both eyes at age 75 years. Ophthalmological examination revealed that her best corrected visual acuity (BCVA) was hand motion $(50 \mathrm{~cm})$ for the right eye and 1.2 for the left eye. Intraocular pressure was $17 \mathrm{mmHg}$ for the right eye and $15 \mathrm{mmHg}$ for the left eye. Both eyes were pseudophakic. Ophthalmoscopy revealed subretinal hemorrhage involving the macular area with retinal macroaneurysm in the center of the hemorrhage (Figure 1A). She was confined to a wheelchair.

Five days after her first visit, the patient underwent pneumatic treatment after providing informed consent. After topical 4\% Xylocaine ${ }^{\circledR}$ and disinfection using potassium iodide solution (diluted at 1:8 with sterile phosphatebuffered solution), intravitreal injection of $100 \%$ sulfur hexafluoride $(0.5 \mathrm{~mL})$ was performed at $3.5 \mathrm{~mm}$ from the corneal limbus. Resting at home while in a 40-degree downward gaze position was prescribed. The patient was asked to gaze at a point on the floor about 1.5-1.8 $\mathrm{m}$ in front of her for 20 minutes each hour. We instructed the patient to maintain this posture for 2 days. At night she was instructed to lay sideways with her head turned down from the side of the affected eye. Three days after gas injection, intraocular pressure was $18 \mathrm{mmHg}$ and no sign of infection was evident. We instructed the patient that the downward gaze posture was no longer necessary.
Three weeks after gas injection, displacement of most of the submacular hemorrhage was observed (Figure 1B). Since the coagulum remained in the center of the original hemorrhage, BCVA was 0.07. Two months later, the coagulum at the macular area was almost absorbed (Figure 1C), and BCVA was 0.1. Retinal macroaneurysm was observed, but laser photocoagulation was not indicated. The macroaneurysm appeared white with no pulsation. Therefore, the macroaneurysm did not appear active and had low risk of recurrent hemorrhage.

\section{Case report 2}

A 58-year-old man presented with blurred vision of his left eye with onset 7 days previously. Initial examination on October 27, 2011 measured a BCVA of 1.2 for the right eye and 0.3 for the left eye. Intraocular pressure was $12 \mathrm{mmHg}$ for the right eye and $10 \mathrm{mmHg}$ for the left eye. Anterior segment and ocular media appeared normal. Ophthalmoscopy revealed subretinal hemorrhage in the macular area and reddish-orange subretinal nodules corresponding to polypoidal choroidal vasculopathy (Figure 2A). Optical coherence tomography (RTvue-100 ${ }^{\circledR}$, Optovue, Freemont, CA) detected an increased retinal pigment epithelial layer. After obtaining informed consent, he underwent displacement of the subretinal hemorrhage as previously described. Intravitreal 100\% sulfur hexafluoride $(0.5 \mathrm{~mL})$ gas injection was performed at $4 \mathrm{~mm}$ from the corneal limbus. Paracentesis was performed to adjust for the transient rise in intraocular pressure. He was asked to maintain a resting position in his home as described for case 1 . Three days after gas injection, intraocular pressure was $10 \mathrm{mmHg}$. Ophthalmoscopy at 5 days after gas injection revealed displacement of hemorrhage downwards and absorbance of part of the submacular hemorrhage. A slight vitreous haze was observed (Figure 2B). Most of the displaced hemorrhage became coagulum. The BCVA of the left eye was 0.5 . Indocyanine green angiography at 12 days

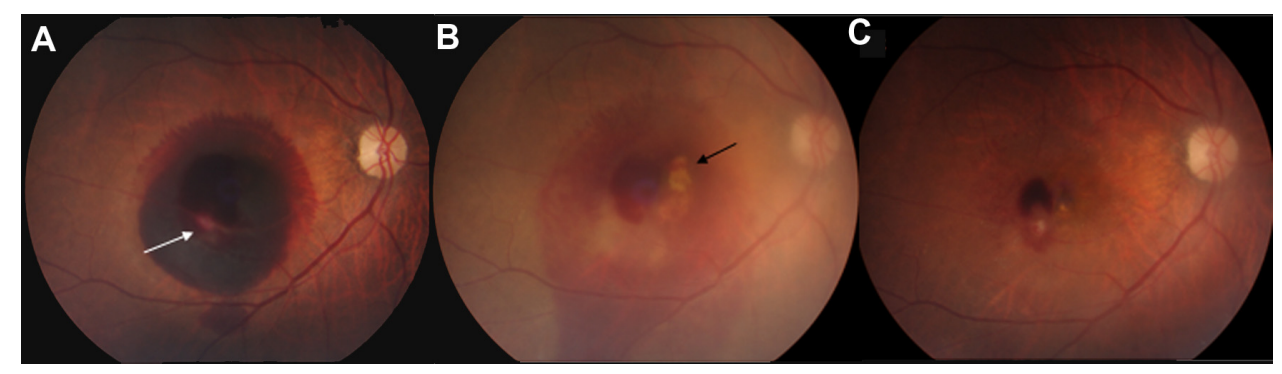

Figure I Case I fundus photograph of the right eye. (A) At the initial visit to the clinic, the fundus showed submacular hemorrhaging with retinal macroaneurysm in the center (arrow). (B) At $2 \mathrm{I}$ days after gas injection, displacement of the submacular hemorrhage was observed and the coagulum remained on the fovea (arrow). (C) At 2 months after gas injection, the submacular hemorrhage was almost totally absorbed when compared with the patient's first visit. 

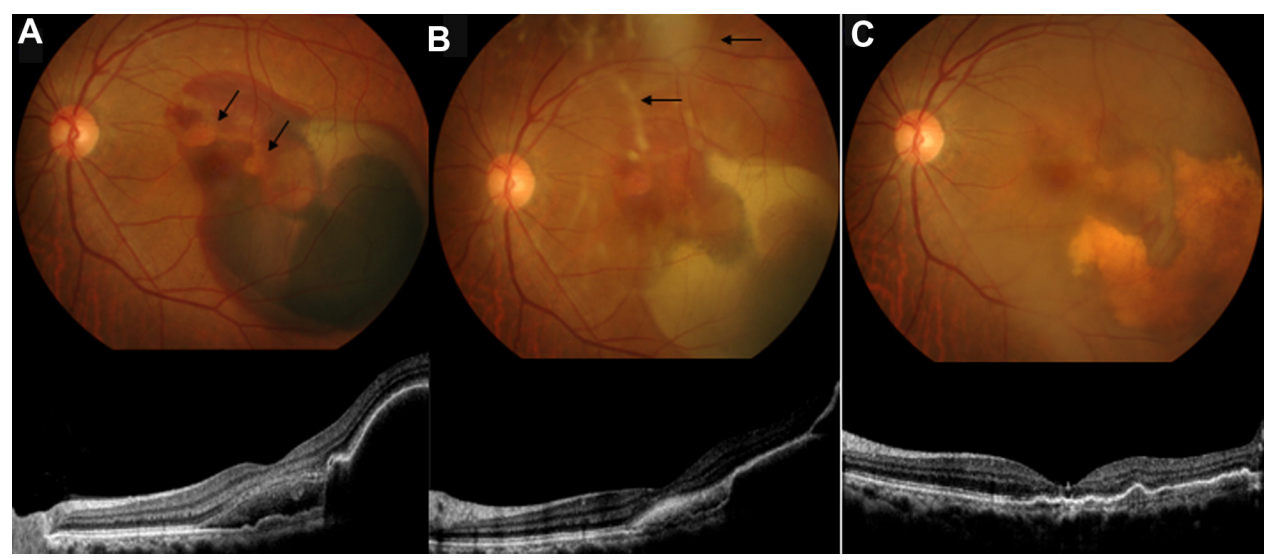

Figure 2 Case 2 fundus photograph and optical coherence tomography imaging of the left eye. (A) At the initial visit to the clinic, the fundus showed submacular hemorrhaging and reddish-orange subretinal nodules corresponding to polypoidal choroidal vasculopathy (arrows). Optical coherence tomography imaging revealed a subretinal hemorrhage and elevation of the retinal pigment epithelial layer. (B) Five days after gas injection, there was displacement of the hemorrhage towards the downward region of the eye and absorbance of a part of the submacular hemorrhage. The displaced hemorrhage became coagulum. Slight vitreous haze was observed (arrows). The elevated retinal pigment epithelial layer was still observable by optical coherence tomography. (C) Two months after gas injection, the submacular hemorrhage disappeared and the vitreous haze was mostly absorbed.

Note: Optical coherence tomography revealed flattening of the retinal pigment epithelial layer at the macula.

after gas injection revealed reddish-orange lesions, which were identified as polypoidal choroidal vasculopathy. At 19 days after gas injection, intravitreal bevacizumab injection (Genentech, San Francisco, CA) at a dose of $1.25 \mathrm{mg}$ was performed. At 2 months after the initial gas injection, submacular hemorrhage disappeared and vitreous haze was also absorbed (Figure 2C). The BCVA of the left eye was 0.9. Optical coherence tomography showed flattening of the retinal pigment epithelial elevations at the macula. The patient did not complain of metamorphopsia and cataract did not develop.

\section{Discussion}

It is generally believed that prone positioning is important to displace submacular hemorrhage. However, prone positioning is not a rational approach with intravitreal gas to displace the subretinal hemorrhage. It was reported that 40-degree downward gaze positioning can drive the subretinal hemorrhage towards the downward region of the eye. ${ }^{6}$ The 40-degree downward gaze positioning is easier to maintain and does not require prone positioning. Prone positioning causes suffering for patients who are older or obese. In the prone position, the buoyancy pushes towards the whole surface of the submacular hemorrhage. However, the buoyancy only requires the superior part of the macula to displace the submacular hemorrhage. A 40-degree downward gaze positioning could potentially cause rotation of the hemorrhage downwards, away from the macular area. The results from our two cases demonstrate that theoretical dynamic movement could work with our method.
In this case report, we did not use intravitreal tissue plasminogen activator. Using this adjuvant, the possibility of displacement of the hemorrhage would be high. However, further investigation of its use may be warranted.

The original method for pneumatic displacement of the subretinal hemorrhage with 40-degree downward gaze positioning was reported by Lincoff et al..$^{5}$ Our method differed by the use of $100 \%$ sulfur hexafluoride injected gas. Injection of $0.2 \mathrm{~mL}$ of $100 \%$ perfluoropropane occupied about $40 \%$ of the vitreous cavity and forced the subretinal hemorrhage downwards during the 40-degree downward gaze positioning. The expansion rate of $100 \%$ perfluoropropane is about four times in the vitreous cavity. ${ }^{7.8}$ Thus, $0.2 \mathrm{~mL}$ of undiluted perfluoropropane will expand to $0.8 \mathrm{~mL}$. In contrast, the expansion rate of $100 \%$ sulfur hexafluoride is approximately 2.5 times. ${ }^{9}$ Therefore, $0.5 \mathrm{~mL}$ of undiluted sulfur hexafluoride will expand to $1.25 \mathrm{~mL}$. We believe that the sulfur hexafluoride gas volume was sufficient to displace the hemorrhage toward the inferior of the macula. When using sulfur hexafluoride gas, the period of posture is only 2 days. This is because the half-life of $100 \%$ sulfur hexafluoride gas in the vitreous is approximately 3 days. We believe that there would be insufficient gas volume to push the submacular hemorrhage at 3 days after gas injection. A strict prone position for a long time was not necessary. Sulfur hexafluoride gas disappears after approximately 7 days in the vitreous cavity. Therefore, sulfur hexafluoride gas provides less risk for cataract development, and can be applied to phakic eyes. An injection of $0.5 \mathrm{~mL}$ of sulfur hexafluoride may cause an initial transient rise in intraocular pressure, but 
it can be managed by paracentesis. Early treatment enables either an improvement of vision or a fundus examination to reveal the cause of the submacular hemorrhage.

\section{Acknowledgment}

The authors thank Professor Mitsuru Sawa for useful advice and for editing this manuscript.

\section{Disclosure}

The authors have no financial conflicts of interests to report in this work.

\section{References}

1. Glatt H, Machemer R. Experimental subretinal hemorrhage in rabbits. Am J Ophthalmol. 1982;94:762-773.

2. Toth C, Morse LS, Hjelmeland LM, et al. Fibrin directs early retinal damage after experimental subretinal hemorrhage. Arch Ophthalmol. 1991;109:723-729.
3. Ohji M, Saito Y, Hayashi A, et al. Pneumatic displacement of subretinal hemorrhage without tissue plasminogen activator. Arch Ophthalmol. 1998;116:1326-1332.

4. Hassan AS, Johnson MW, Schneidermann TE, et al. Management of submacular hemorrhage with intravitreal tissue plasminogen activator injection and pneumatic displacement. Ophthalmology. 1999;106:1900-1906.

5. Lincoff H, Kreissig I, Stopa M, et al. A $40^{\circ}$ gaze down position for pneumatic displacement of submacular hemorrhage. Clinical application and results. Retina. 2008;28:56-59.

6. Stopa M, Lincoff A, Lincoff H. Analysis of forces acting upon submacular hemorrhage in pneumatic displacement. Retina. 2007;27:370-374.

7. Lincoff H, Coleman J, Kreissig I, et al. The perfluorocarbon gases in the treatment of retinal detachment. Ophthalmology. 1983;90:546-551.

8. Peters MA, Abrams GW, Hamilton LH, et al. The non-expansile, equilibrated, concentration of perfluoropropane gas in the eye. Am J Ophthalmol. 1985;100:831-839.

9. Abrams GW, Edelhauser HF, Aaberg TM, et al. Dynamics of intravitreal sulfur hexafluoride gas. Invest Ophthalmol Vis Sci. 1974;13:863-868.
Clinical Ophthalmology

\section{Publish your work in this journal}

Clinical Ophthalmology is an international, peer-reviewed journal covering all subspecialties within ophthalmology. Key topics include: Optometry; Visual science; Pharmacology and drug therapy in eye diseases; Basic Sciences; Primary and Secondary eye care; Patient Safety and Quality of Care Improvements. This journal is indexed on

Submit your manuscript here: http://www.dovepress.com/clinical-ophthalmology-journal

\section{Dovepress}

PubMed Central and CAS, and is the official journal of The Society of Clinical Ophthalmology (SCO). The manuscript management system is completely online and includes a very quick and fair peer-review system, which is all easy to use. Visit http://www.dovepress.com/ testimonials.php to read real quotes from published authors. 